\title{
Screen time as an index of family distress
}

\author{
Joshua K. Hartshorne ${ }^{1}$, Yi Ting Huang ${ }^{2}$, Pablo Martín Lucio Paredes Aulestia ${ }^{3}$, Kathleen Oppenheimer ${ }^{2}$, \\ Parker T. Robbins ${ }^{1}$, \& María Daniela Velasco Molina ${ }^{3}$ \\ ${ }^{1}$ Department of Psychology and Neuroscience, Boston College \\ 2 Department of Hearing and Speech Sciences, University of Maryland \\ ${ }^{3}$ Reelgood
}

\begin{abstract}
The increase in children's screen time over the last few decades has concerned parents, educators, and policymakers alike, due to its association with negative developmental outcomes. Interventions have focused on educating parents about the apparent dangers and coaching them on how to limit screen time. Such interventions are unlikely to be effective if screen time is driven less by parental preference than by parental necessity, supplementing insufficient adult caretaker availability. We show that during the COVID crisis, screen time in the United States increased dramatically as a direct result of sudden decrease in adult caretaker availability. This indicates that lower screen time rates prior to the pandemic were not (merely) a function of well-informed parenting but of well-resourced parenting. We discuss implications for policy, as well as for the ongoing scientific debate about whether screen time is actually problematic for development.
\end{abstract}

Keywords: COVID-19, screen time, child development

\section{Introduction}

As lock-downs proliferated in late winter, there has been extensive discussion about their effects on children - among policy-makers, educators, scientists, parents, and the public at large (Bauer, 2020; Masonbrink \& Hurley, 2020; Van Lancker \& Parolin, 2020). Increases in screen time have been of particular concern, driven by research connecting excessive child screen time to poor sleep, myopia, metabolic syndromes, behavioral challenges, decreased physical activity, and other negative outcomes (Adelantado-Renau et al., 2019; American Academy of Pediatrics, 2020; Guan et al., 2020, 2020; Madigan, McArthur, Anhorn, Eirich, \& Christakis, 2020; Moore et al., 2020; Oswald \& Moore, 2020; ParentsTogether, 2020; Stiglic \& Viner, 2019; but see Ferguson, 2017).

Based on such findings, many authorities caution parents against screen time (American Academy of Pediatrics, 2016; Bauer, 2020; Guan et al., 2020; World Health Organization, 2019). Such interventions only make sense if screen time is largely a matter of parental preference or knowledge of the risks. It is not clear this is the case. While increased screen time in adolescents correlates with parental feelings towards screen time (Lauricella \& Cingel, 2020), causality could run either direction, and both common experience and empirical research suggest alternative/additional explanations. Most notably, parents report using media as a distraction when they need to attend to other matters or take a break (Nikken, 2019). Indeed, increased screen time is associated with a broad range of factors that limit parental resources and access to child care (including education), such as low socioeconomic status, identification as a racial minority, diminished social support for parents, and poor maternal mental health (Johnson \& Padilla, 2019; Nikken, 2019; Pempek \& McDaniel, 2016; Przybylski \& Weinstein, 2019; but see Bank et al., 2012).

Thus, screen time may actually be a function of child care pressure: parents who cannot fully meet their child care needs either themselves or through external support turn to screens as the babysitter of last resort. If so, warning parents about screen time may not produce much beyond parental guilt.

Interestingly, it is not clear that screen time causes poor developmental outcomes, and for similar reasons. Notably, the aforementioned factors that are associated with increased screen time (e.g., low socioeconomic status) are themselves associated with poor developmental outcomes, and thus may jointly cause both screen time and poor outcomes (Ashton \& Beattie, 2019; Viner, Davie, \& Firth, 2019). Even if screen time is part of the causal chain, it may not be determinative: the relationship between screen time and poor outcomes may be driven by associated activities, such as snacking and sedentariness (Viner et al., 2019).

The gold standard for showing a causal relationships is an intervention study. Unfortunately, successful interventions on screen time have been rare, difficult to scale, and rarely followed up long-term (Schmidt et al., 2012) - all of which may itself be suggestive. Other possible causes (low socioeconomic status, limited availability of child care, etc.) are even harder to experimentally intervene on, at least in normal circumstances.

For better and worse, these are not normal circumstances. The 


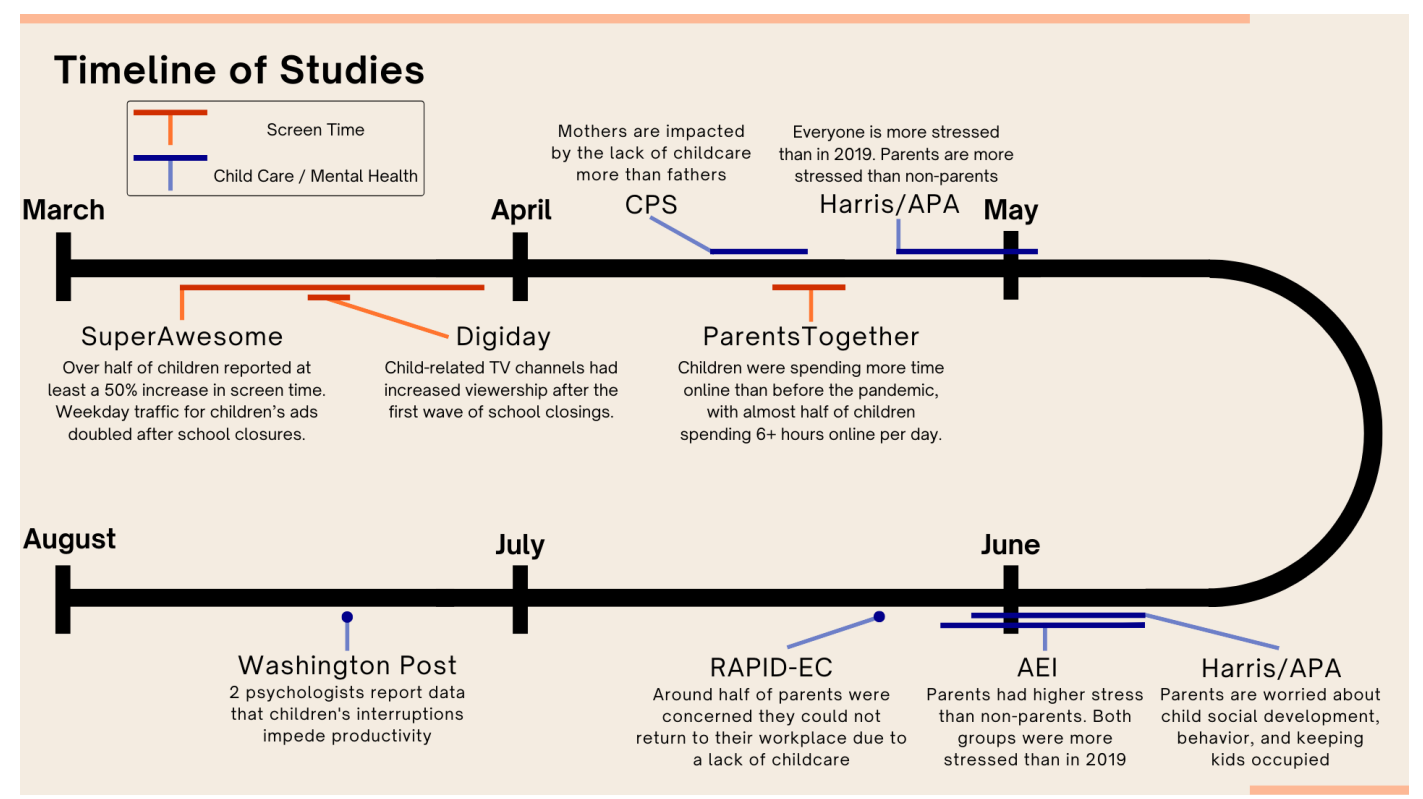

Figure 1. Timeline of data on changing family circumstances during the COVID-19 pandemic. SuperAwesome (SuperAwesome, 2020). Digiday (O'Reilly, 2020). CPS: Current Population Study (Collins et al., 2020). ParentsTogether (ParentsTogether, 2020). Harris/APA: Harris/American Psychological Association (American Psychological Association, 2020a, 2020b). AEI: American Enterprise Institute (Cox \& Abrams, 2020). RAPID-EC (Fisher, Lomardi, \& Kendall-Taylor, 2020). Washington Post (Edwards \& Snyder, 2020).

closure of daycares and schools has increased the child care burden on millions of parents. This is particularly true for parents who are not just monitoring their children, but effectively home-schooling them. This should hardly matter if screen time is primarily a function of parental knowledge/preference. However, if the causal determiner is child care pressure, we should see closely time-locked effect. Thus, in this study, we use the pandemic to probe the relationship between child care pressure and screen time. We conclude by discussing implications for policy and for science.

Note that we use the term "child care" broadly, to include all aspects of child-rearing, including education. \# Prior Work

Early evidence suggests that the COVID-19 crisis has increased parental stress while reducing parents' access to external child care (including school). In mid-March, daycares and schools shuttered, and parents had difficulty finding alternatives. On June 7, RAPID-EC reported that $47 \%$ of parents of children under 5 had lost access to their pre-pandemic child care and $67 \%$ were now the sole child care provider, based on a nationally-representative sample of approx. 1000 households (RAPID-EC Research Group, 2020). As a result, $47 \%$ were forced to work from home, with predictable consequences for productivity (Collins, Landivar, Ruppanner, \& Scarborough, 2020; Edwards \& Snyder, 2020). This burden fell disproportionately on mothers, who reduced their work hours 4-5 times more than fathers, according to the US
Current Population survey (Collins et al., 2020).

Not surprisingly, several studies found that parents' stress had increased and was greater than that of non-parents (American Psychological Association, 2020a; Cox \& Abrams, 2020; Fisher et al., 2020). In addition to worrying about health and finances, parents reported concerns about the effect of the pandemic on their child's social development (71\%) and their ability to keep their child occupied (60\%), according to a lateMay APA/Harris nationally-representative survey $(\mathrm{N}=3013)$ (American Psychological Association, 2020a). (Note that these findings do no necessarily mean parents have been more affected than non-parents; even pre-pandemic, parents report lower well-being than non-parents (Glass, Simon, \& Andersson, 2016; Hansen, 2012).

Preliminary evidence suggests a significant increase in child screen time (Moore et al., 2020; O'Reilly, 2020; ParentsTogether, 2020; SuperAwesome, 2020). Viewership of childrelated TV channels increased in the immediate wake of the pandemic (O'Reilly, 2020). SuperAwesome, a kid-safe advertising service, reported kids' weekday traffic in the US and the UK approximately doubled in mid-March (SuperAwesome, 2020). In March, a small survey of children $(200<\mathrm{N}<$ 400 ) found $52 \%$ of 6-9 year olds and 56\% of 10-12 year olds reported an increase in screen time of $50 \%$ relative to pre-pandemic (SuperAwesome, 2020). In mid-April, $49 \%$ of parents $(\mathrm{N}>3000)$ reported their children spending more than 
6 hours per day online, with $26 \%$ reporting more than 8 hours, compared to $8 \%$ an $4 \%$, respectively, before the pandemic (ParentsTogether, 2020). Small studies in Canada, China, and South Korea showed similar patterns (Guan et al., 2020; Moore et al., 2020; Xiang, Zhang, \& Kuwahara, 2020). These increases have not gone unnoticed, with $85 \%$ of respondents in the ParentsTogether survey reporting concern about their children's screen time (ParentsTogether, 2020).

\section{Limitations}

The results above strongly suggest that during the pandemic, child care pressures and child screen time both increased. However, it is unclear that the former caused the latter. Many other things increased during the same time period, including COVID cases, parental stress, unemployment, and time spent at home. Stronger evidence would come from showing that child care is more tightly linked with screen time both temporally or geographically than are other factors, or showing a dose-dependent response (screen time increases in proportion to child care difficulties). Unfortunately, prior studies are toorestricted and scattered temporally to allow for clean comparisons (the streaming data in particular is restricted to a few weeks in late March / early April; cf. Figure 1), and they do not address geography or dose dependence. We address these limitations below.

\section{Method}

We aimed simply to measure the critical phenomena - screen time, child care pressure, parental mental health - in the United States during the early months of the pandemic with as much temporal and georaphic precision as possible by collecting as much data as possible. Ultimately, we were able to obtain eight large data sets relevant to these questions: two of which we collected ourselves and six of which we sourced from third-parties. All data sets involved at least 1,000 participants, and some are orders of magnitude larger. Thus, although the unprecedented nature of pandemic-era social distancing complicates any formal power analysis, all the statistical tests reported in the Results are well-powered for all but fairly small effects. Given the nature of the questions at hand, small effects are of correspondingly small interest. More importantly, the eight data sets contain a number of complementary measures, allowing us to assess the robustness (or not) of our data by comparing findings across data sets.

\section{Kaiser Health Tracking Polls}

The Kaiser Family Foundation's (KFF) Health Tracking Poll is a nationally-representative phone survey conducted monthly, with two rounds in March 2020. Our analyses focus on the four iterations that included data about parental stress and/or child care: March 11-15 (Hamel, Lopes, et al.,
2020), March 23-30 (Kirzinger, Kearney, Hamel, \& Brodie, 2020), May 13-18 (Hamel, Kearney, et al., 2020b), July 1419 (Hamel, Kearney, et al., 2020a). Combined, this data set included 1310 parents or legal guardians of children under 18 and 3626 non-parents. There were no repeat respondents across the samples. Surveys were in English or Spanish, as needed. Each survey included an oversample of prepaid cell phone numbers ( $25 \%$ of cell phone numbers), in order to better recruit low-income and non-White participants. The July survey included an oversample of parents $(\mathrm{N}=101)$. Our analyses focused on raw numbers, rather than responses weighed by KFF's population model.

\section{AP-NORC}

The Associated Press-NORC Center for Public Affairs Research (AP-NORC) conducted two nationally-representative surveys in 2020 that identified parents: March 26-29 (Associated Press-NORC Center for Public Affairs Research, 2020b) and July 16-20 (Associated Press-NORC Center for Public Affairs Research, 2020a). Most interviews were conducted by Web, with a smaller number conducted by phone. Surveys were in English or Spanish, as needed. These two surveys included 337 parents or legal guardians of children under 18 in March, and 250 parents or legal guardians of children who normally attended daycare, primary school, or secondary school in July. These subsets were the focus of our analyses. Our analyses focused on raw numbers, rather than responses weighed by AP-NORC's population model.

\section{CovidImpact Survey}

NORC at the University of Chicago, funded by the Data Foundation, conducted the COVID-19 Household Impact Survey in three iterations: April 20-26 (2096 parents, 6694 nonparents), May 4-10 (2093 parents, 6881 non-parents), and May 30-June 8 (1807 parents, 5698 non-parents) (Wozniak, Willey, Benz, \& Hart, 2020). The survey used a questionnaire to measure physical health, mental health, economic security, and social dynamics across the US. Surveys were in English or Spanish, as needed. The survey consisted of a national survey and regional surveys. The national survey data was conducted by mail, email, telephone, or field interview in the 50 states and Washington DC. The regional survey was conducted by web or phone in 18 regional areas, consisting of 10 states (CA, CO, FL, LA, MN, MO, MT, NY, OR, TX) and 8 Metropolitan Statistical Areas (Atlanta, Baltimore, Birmingham, Chicago, Cleveland, Columbus, Phoenix, Pittsburgh). Our analyses focused on raw numbers, rather than responses weighed by NORC's population model.

Three questions addressed mental health: respondents were asked to describe how frequently they had experienced anxiety, depression, and helplessness in the past week (" $<1$ day", 

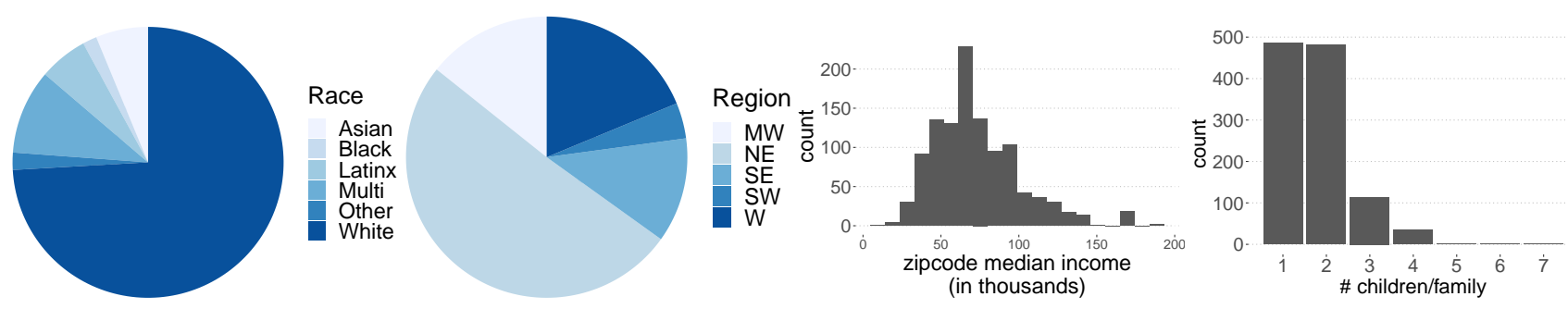

Figure 2. Demographics of KidTalk survey. Far Left: Race. Note that for purposes of the race pie chart (left), 'Latinx' was treated as a race because most respondents self-identifying as Hispanic or Latinx did not additionally identify as Black, White, or Native American. Middle Left: Residence, by region of USA. Middle Right: Histogram of median income of zipcode of respondent. Note that to encourage participation, we did not ask for SES information directly. Far Right: Histogram of number of children living with respondent, per respondent.

"1-2 days", "3-4 days", "5-7 days"). We converted this to a numeric score (1-4) and averaged across the three questions.

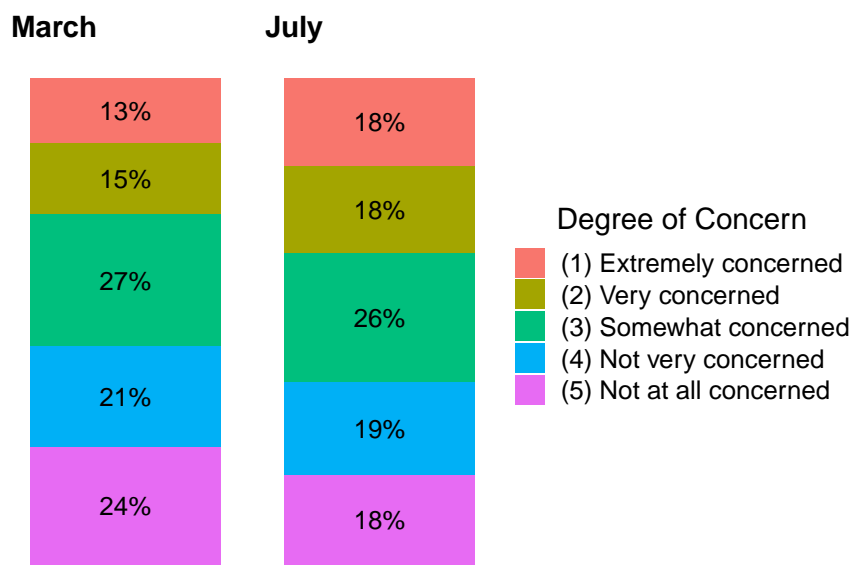

Figure 3. Parental concerns about holding down a job without child care in March (left) and addressing non-child responsibilities in July (right). From the AP-NORC.

\section{Understanding America Study: Coronavirus in America Survey}

The Understanding American Study began a tracking survey of COVID-related issues on 03-10-2020, repeating every two weeks (Alattar, Messel, \& Rogofsky, 2018; Understanding America Study, 2020). Among other things, participants were asked to report the frequency of four negative mental health experiences (anxiety, worry, depression, and lack of interest) on a four-point scale. For analysis, we used a composite score of "mental health strain" (the sum of the four individual items).

Here, we included data collected up through 07-20-2020: 55599 responses from a demographically representative sample of 7650 American residents 18 years of age or older. Of these, we focused analyses on the 19672 responses from 2331 individuals who reported that there was a child $(<18$ years old) in their household. While these as not necessarily all parents or guardians of the children in the household, it is likely that most are, and for shorthand we refer to them as "parents" below. Because we compare the mental health data from this study against other national data, here we do use the demographic weights supplied by Understanding America. Note that throughout this data set, parents report higher levels of distress than non-parents; however, we do not report details of this comparison below because there is no pre-COVID baseline of comparison, making it impossible to report whether this difference is larger than the one normally observed prepandemic (cf. Nomaguchi, 2012).

\section{KidTalk Survey}

The KidTalk Survey was conducted by our research group in conjunction with the KidTalk Project (http://kidtalkscr apbook.org), from April 16 to September 11, with 94\% of responses coming by June 15 . The survey was conducted online in English and Spanish using Qualtrics. Specific effort was made to recruit USA-based parents of children living at home. In all, we collected 1391 responses, including 1120 USA-based parents, who are the focus of our analyses. Note that this excludes 10 respondents who gave invalid US ZIP codes. Demographics of this subset are shown in see Figure 3. $9 \%$ of respondents reported having participated previously. Because the survey was fully anonymous, it is not possible to align multiple responses by the same individual. Any analyses that exclude repeat respondents are identified as such below. Note that while questions initially asked parents to compare their situation to a similar day before the crisis, in June this was switched to compare to a similar day the previous year (to account for summer schedules).

\section{Reelgood Streaming Data}

Reelgood (reelgood.com/business/products/catalog/) is a streaming service guide, allowing users to find and play content from a wide array of streaming providers. We tracked number of initiations of child-related content from the Dec. 30, 

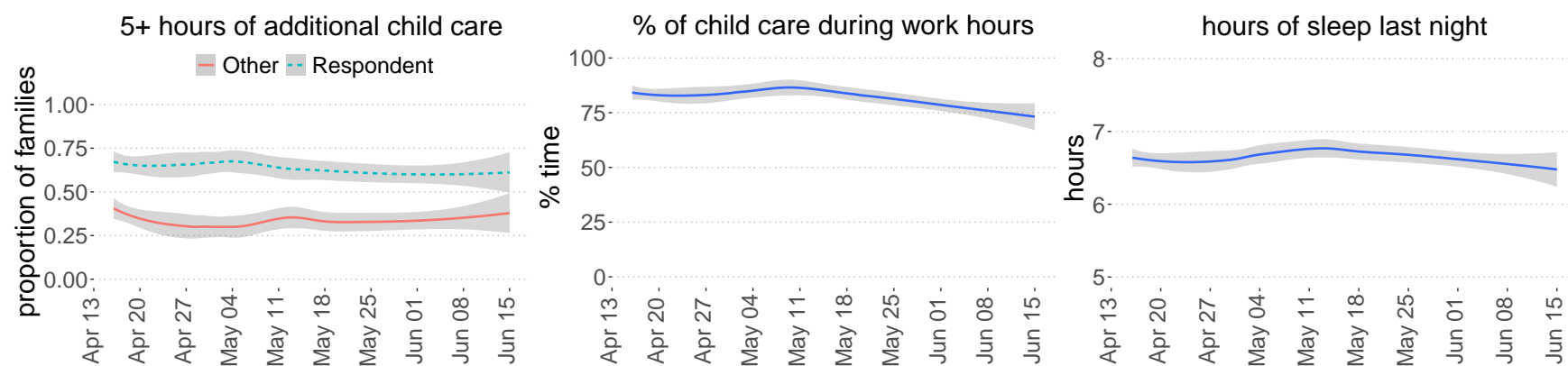

Figure 4. Results from KidTalk Survey. Graphs focus on April 16 to June 15, when most of the data was collected. Lines are smoothed LOESS curves. Shaded areas represent $+/-1$ standard deviation. Left: KidTalk respondents reporting that they (dashed) or another household member (solid) were performing 5+ additional hours/day of child care. Center: For respondents reporting performing additional child care, percentage that occurs when they would normally be working. Right: Respondent's hours of sleep the previous night.

2019 , to July 19,2020 , separately for each state. Data were limited to user accounts that streamed child-related content at some point during the period. In order to protect businesscritical information about user numbers, we calculated for each week the percentage change in initiations, relative to a baseline. Three baselines were considered: the average across weeks, the second ${ }^{1}$ week in the period, and the average during the "pre-quarantine period" (the first 11 weeks). In practice, the choice of baseline has little effect, and so we use the first one (average across weeks) for primary analyses. Results using the other baselines can be explored in the online interactives (see below).

\section{Other Data}

We use the school closure dates provided by $\mathrm{MCH}$ Strategic Data (www.mchdata.com/). Data on COVID rates comes from the New York Times (New York Times, 2020). Population estimates for each state come from the 2019 Census report (U.S. Census Bureau, 2019). Time spent at home comes from the Google Community Mobility Reports, which estimates time spent by Google users in each of several categories of locations (residence, workplace, etc.) (Aktay et al., 2020). Numbers are reported in terms of relative change compared to a baseline of Jan 3 to Feb 6, 2020.

\section{Results}

Online Interactive Figures $\quad \mathrm{S} 1$ (jkhartshorne.shinyapps.io/Spaghetti/) and S2 (jkhartshorne.shinyapps.io/Heatmap/) allow for in-depth exploration of how screen time, COVID rates, and stress levels changed with time on a state-by-state basis. Source code for all analyses are included as part of this reproducible document at osf.io/swzun. The KidTalk survey and data are available at osf.io/dyw3t/. Other data are available from other sources (see citations above), with the exception of the Reelgood streaming data, which remains private.

\section{$1.00-$}

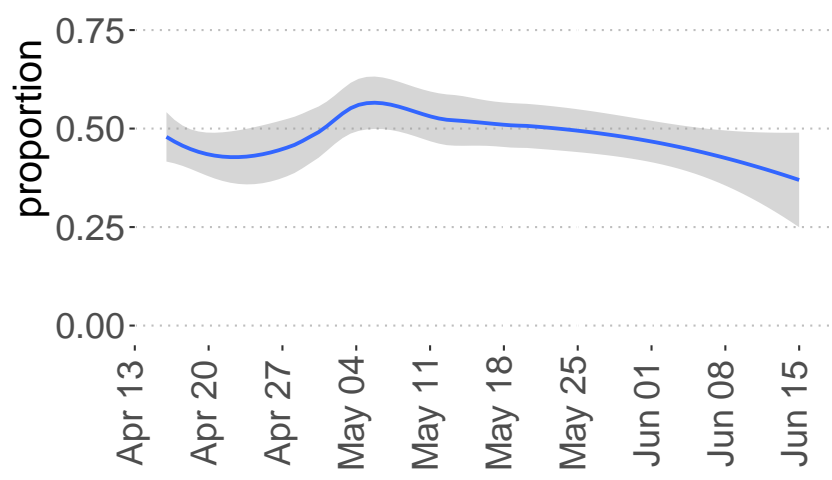

Figure 5. Proportion of respondents in KidTalk survey reporting that their youngest child engaged in at least 2 additional hours of screen time yesterday, relative to a similar day preCOVID. The line is a smoothed LOESS curve. Shaded areas represent $+/-1$ standard deviation.

The bulk of school closures occurred between March 11 and March 19, with some schools and daycares closing earlier (Decker, Peele, Riser-Kositsky, Kim, \& Patti Harris, 2020). In mid-March, KFF found that $36 \%\left(\mathrm{CI}^{2}:[32 \%, 42 \%]\right)$ of parents had lost child care. Only a week later, AP-NORC found much higher numbers (83\%, CI: [78\%, 86\%]). Critically, 63\% (CI: $[57.00 \%, 69 \%])$ of these were working parents whose employment status - and the employment status of others in the household - had not changed. Similarly, CovidImpact found that $65 \%$ (CI: [63\%, 67\%]) of parents had lost child care by late April, of whom 73\% (CI: [71\%, 75\%]) had not lost employment or hours. CovidImpact found similar numbers in

\footnotetext{
${ }^{1}$ The first week in the period has unusual activity due to its overlap with the New Year holiday, and thus provides a poor baseline.

${ }^{2}$ All confidence intervals are $95 \%$
} 

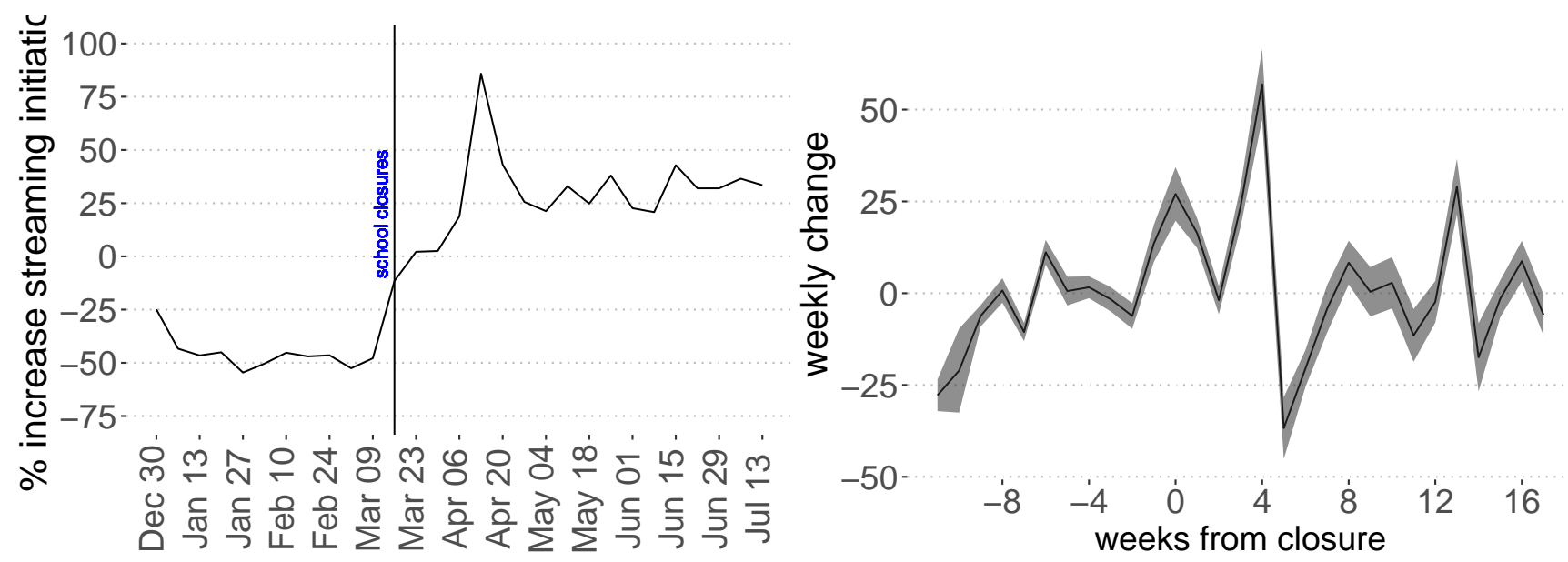

Figure 6. Reelgood streaming data. Left: Changes in streaming, averaged across states. Baseline is average for each state across the time period. Note that uncertainty measures are not available for the Reelgood state averages. Right: Average weekly change, across states. Shaded areas represent $+/-1$ standard deviation.

early May (62\%, CI: [60\%, 64\%]; 77\%, CI: [75\%, 79\%]) and early June (52\%, CI: [50\%, 54\%]; 77\%, CI: [74\%, 80\%]).

In many cases, parents without child care were working from home. In the late March AP-NORC survey, $41 \%$ (CI: [35\%, $47 \%]$ ) of those who had lost child care reported that they or someone in their household was working from home. Substantial numbers were similarly reported by CovidImpact for late April (53\%, CI: [50\%, 55\%]), early May (50\%, CI: [47\%, $53 \%]$ ), and early June (45\%, CI: [41\%, 48\%]).

In March, 53\% (CI: [48\%, 58\%]) of KFF respondents ( $\mathrm{N}=$ 351) thought it would be difficult to find alternative child care if their school or daycare closed. This appears to have been prescient: A consistent majority of KidTalk respondents reported doing $5+$ additional hours of child care per day, the vast majority of which was during the hours they would normally be working (Figure 4). Of the March AP-NORC respondents who were asked ( $\mathrm{N}=165)$, over half $(55 \%, \mathrm{CI}$ : [48\%, 63\%]) reported being somewhat, very, or extremely concerned about maintaining their job while taking care of their child (see Figure 3, Left). Similar results were found in July: all 250 responding parents were asked more generally about their level of concern as to maintaining non-child responsibilities, with $62 \%$ (CI: $[56 \%, 68 \%$ ) indicating they were somewhat, very, or extremely worried (see Figure 3, Left). KFF reported converging results: In July, 48\% (CI: [42\%, 53\%) of parents of school-aged children were somewhat or very worried about being able to pay sufficient attention to their children while working from home if school did not reopen. Interestingly, None of these results was significantly modulated by parent gender (March AP-NORC: $\mathrm{t}(155.50)=-1.05, \mathrm{p}=.294$; July AP-NORC: $\mathrm{t}(134.60)=-1.89, \mathrm{p}=.061$; July KFF: $0.74, \mathrm{p}=$ .458; Note KidTalk respondents did not report gender).
Reelgood data revealed a dramatic increase in streaming of child-related content in March (Figure 6). The right-hand side of Figure 6 shows week-to-week change averaged across states, relative to the week in which a state-wide shutdown order went into effect. The relative changes were significantly different from zero after correcting for multiple comparisons (ps < .00177) at weeks -7, -6, 0, 1, 3, 4, 5, 6, and 13.

Analyses revealed that these changes closely tracked changes in child care. The largest spike (weeks 0,1 , and 3-5) matches the timing of school closure. Interestingly, there is a significant decline in weeks 5 and 6 , consistent with the timeline for the wide-spread start of online learning: The percentage of school districts offering at least some online instruction rising from $10 \%$ on March 26 to $56 \%$ on April 21 (Lake \& Dusseault, 2020). The declines in at weeks -7 and -6 coincide with the end of Winter Break in early January, and the small increase in Week 13 coincides with the end of (online) school in early/mid June. Relatedly, KidTalk survey respondents who had lost child care reported a greater increase in screen time for their youngest child (parents were only asked about the youngest child) than parents who had not lost child care $(\mathrm{t}(246.20)=6.58, \mathrm{p}<.001$, Cohen's $\mathrm{d}=0.80)$. Note that the exact numbers here are not meaningful: throughout the primary time period, around half of parents chose this maximum response (Figure 5) - which, due to excessive optimism, was an increase of " $2+$ hours". Perhaps for this reason, the evidence of a dose-dependent response was weak: the correlation between additional hours of child care and additional screen time did not quite reach significance $\left(\mathrm{T}_{\mathrm{B}}=\right.$ $0.05, \mathrm{p}=.069, \mathrm{CI}:[0,0.09]$, Cohen's $\mathrm{d}=0.14$ ).

In contrast, national averages show little relationship between screen time and COVID rates: While both screen time and COVID rates were low at the beginning of the period and 


\section{Streaming}

2020-03-02

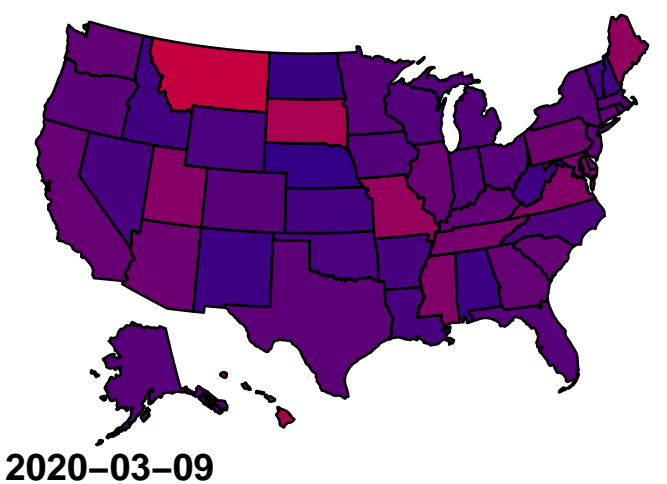

2020-03-09

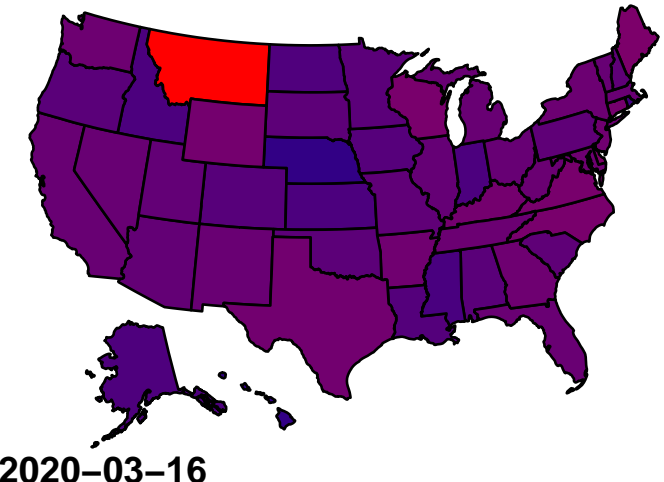

2020-03-16

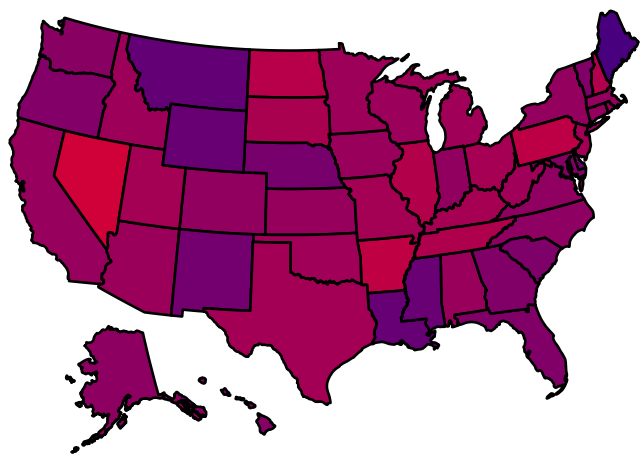

$\%$ change

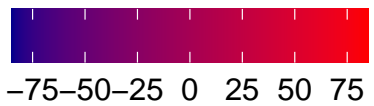

Weekly COVID cases (per 100,000)

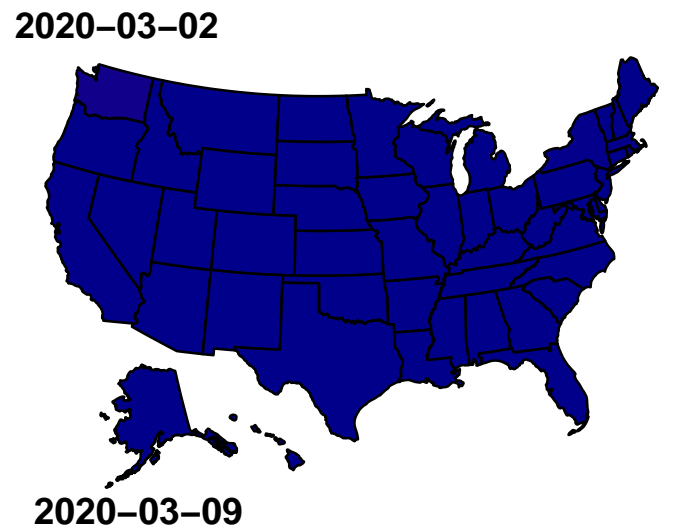

2020-03-09
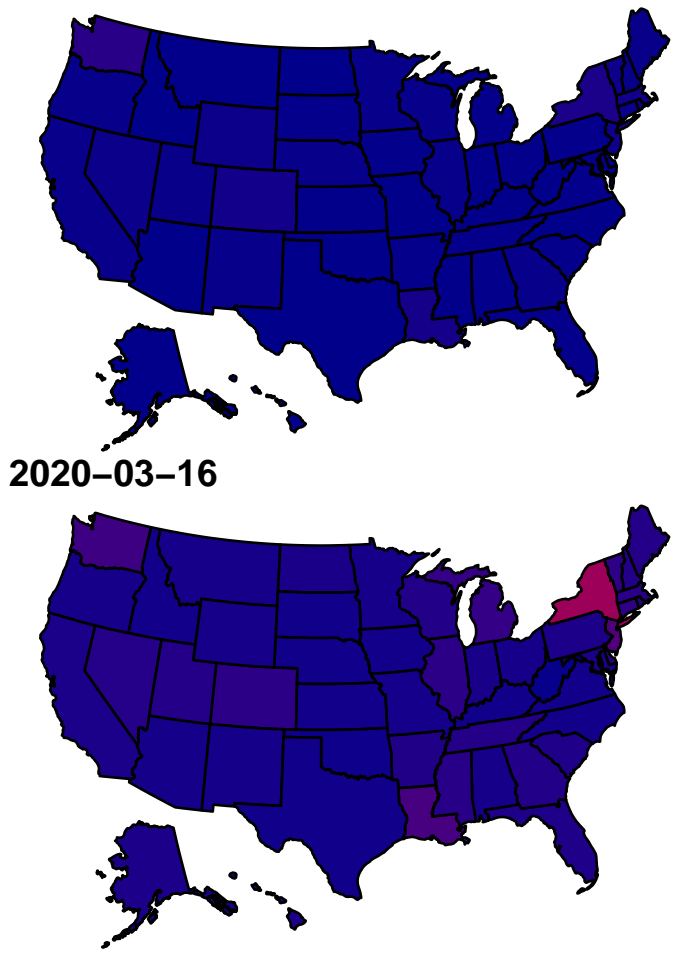

Cases

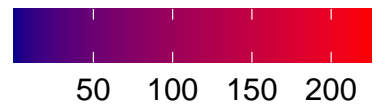

Figure 7. Left: Change in frequency of streaming content, relativized to that state's average across the time period. Right: COVID-19 cases per hundred thousand, for each state. Note: Color scales are different for the two data sets.

high at the end, the relationship is otherwise tenuous (Figure 8 , top). State-by-state analyses cast further doubt on a relationship. Strikingly, the sudden increase in screen time was broadly observed across the country, even as COVID was largely confined to a few states (Figure 7): when screen time levels hit their maximum in early April, most states were still reporting minimal levels of infection. In no week was the correlation between COVID rates and screen time across states significant, after correcting for multiple comparisons (ps>.0024). Entering COVID and screen time data for each state during each week, there is an overall correlation $(\mathrm{r}(1426)$ $=0.43$, CI: [0.39, 0.47], $\mathrm{p}<.001$, Cohen's $\mathrm{d}=0.95$ ). However, this correlation largely disappears after regressing out the proportion of schools still in session $(\mathrm{r}(1426)=0.10, \mathrm{CI}$ : $[0.05,0.15], \mathrm{p}<.001$, Cohen's $\mathrm{d}=0.21$ ). (Note that because school closures often occurred during the middle of the week, 
we did not include the week of the state-wide school closure order in these or related correlations.)

Similarly, screen time did not closely track how much time parents were spending at home (Figure 8, middle). Again, when considering rates for each state and at each week, there is an overall correlation between screen time and time spent at home $(\mathrm{r}(1098)=0.51, \mathrm{CI}$ : [0.46, 0.55], $\mathrm{p}<.001$, Cohen's $\mathrm{d}=$ 1.18); again, however, this largely disappears after regressing out the proportion of schools session $(\mathrm{r}(1098)=0.07, \mathrm{CI}$ : [0.01, 0.13], $\mathrm{p}=.016$, Cohen's $\mathrm{d}=0.15)$.

Looking at national averages, parental mental health (from Understanding America) does not closely track screen time (Figure 8, bottom). (We do not have state-by-state data and thus could not perform correlation analyses like those above.) In contrast, poor mental health does seem to be predicted by child care pressure. In line with findings reviewed above, KFF respondents were more likely to think the COVID crisis had affected their mental health if they had children at home (mean of 0.63 on a scale of 0,1 , or 2 ) than if not (mean $=0.55$; $\mathrm{t}(2215)=3.10, \mathrm{p}=.002$, Cohen's $\mathrm{d}=0.10)$. However, in the March sample (the only one to ask about loss of child care), the 129 parents who had lost child care were more likely to say the crisis had affected their mental health $($ mean $=0.61)$ than the 216 who had not $(\mathrm{N}=216$, mean $=0.40 ; \mathrm{t}(238.20)=$ $2.50, \mathrm{p}=.013$, Cohen's $\mathrm{d}=0.30)$, which was itself similar to that of non-parents $(\mathrm{N}=849$, mean $=0.42, \mathrm{t}(340.70)=-0.40$, $\mathrm{p}=.718$, Cohen's $\mathrm{d}=0$ ). Identical patterns of results (and significance) were found for all three CovidImpact data sets. Of particular interest, the KidTalk data shows a dose-dependent response: the more extra hours of child care the respondent reported, the more they reported worrying about things in general $\left(\mathrm{T}_{\mathrm{B}}=0.08, \mathrm{p}=.001, \mathrm{CI}\right.$ : [0.03, 0.13], Cohen's $\mathrm{d}=$ $0.26)$.

\section{Discussion and Conclusion}

We confirmed and extended prior findings that child screen time use increased during the COVID crisis. We additionally showed that the increase was time-locked to changes in child care pressure and is greater for families that lost child care (dose dependence). Critically, other pandemic-related changes (COVID rates, time spent at home, parental mental health strain) were not as closely associated with screen time and thus must play a smaller role, if any.

Interestingly, the previously-described differential mental health impact of the pandemic on parents appears to be itself driven by child care pressure. This finding is consistent both with intuition and some prior evidence that availability of sufficient child care support and parental leave decreases parental stress and improves well-being (Glass et al., 2016; Parkes, Sweeting, \& Wight, 2015). Thus, the known association between poor maternal mental health and screen time

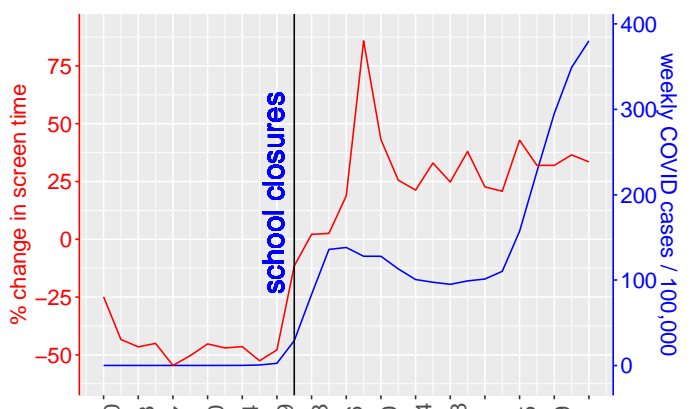

ㅇำ
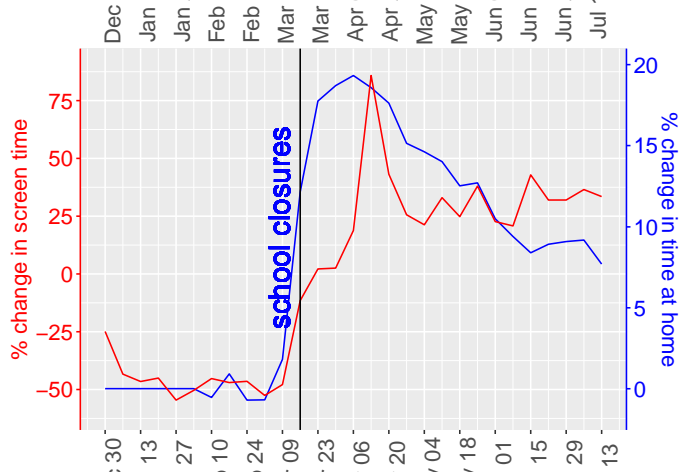

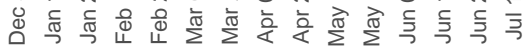

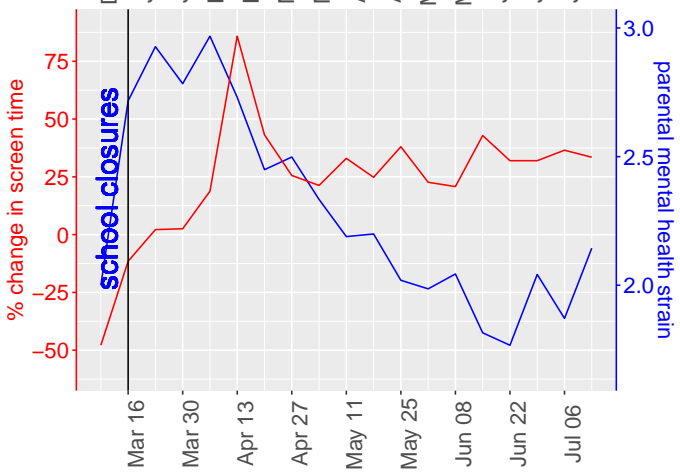

Figure 8. From top to bottom: changes in COVID rates (NY Times), time spent at home (Google Mobility), parental distress (Understanding America). School closures and changes in screen time (Reelgood) are overlaid.

(Johnson \& Padilla, 2019) may itself be a common effect of child care pressure.

It remains an open question how much of the association between screen time and negative child development outcomes is explained by child care pressure. As noted above, the correlational nature of extant data makes this difficult to disentangle. Conveniently - from a scientific standpoint, not a societal one - the present crisis provides an opportunity to test this question as well. We are currently collecting data on how language development - often argued to be impeded by screen time - has been impacted by the pandemic (http://kidtalkscrapbook.org), but that is only one of a large 
number of questions that needs to be addressed.

\section{Limitations of Generalizability}

Given that our core findings were confirmed across multiple large and often nationally-reprsentative data sets means that they should generalize well to the United States during the pandemic at a population level. Effect sizes may vary for different demographic subgroups, perhaps due to confounding factors (baseline prevalence of screen availability, adult caretaker availability, parental mental health disorders, etc.). Similarly, these findings may not generalize to other societies or subgroups in our own society where adult supervision of children is not the norm. Similarly, while our findings suggest that child care pressure is a factor in screen time and parent mental health outside the pandemic era, we do not have any direct evidence. For this, a causal intervention study is critical.

\section{Implications for Policy}

Public policy around screen time has focused on educating parents about its (suspected) negative effects and coaching parents on how to enforce screen time limits (American Academy of Pediatrics, 2016; Bauer, 2020; Guan et al., 2020; World Health Organization, 2019). The present findings raise serious questions about the efficacy of such an approach. Millions of parents did not suddenly in March 2020 change their minds about the dangers of screen time or forget how to institute controls; they lost child care support. This finding is consistent with pre-pandemic research (reviewed above) pointing to a connection between child care pressure and screen time. While we cannot say definitively that coaching parents on limiting screen time would have no effect (we did not test this possibility), it stands to reason that addressing the root causes of increased screen time (namely child care pressure) would work better - though this needs to be empirically shown.

As already noted, we have no direct evidence that ameliorating child care pressure outside the pandemic era would affect screen time. That said, ameliorating child care pressure would have substantial benefits for children and families regardless. If nothing else, it would mean richer adult interactions for children and less strain on parents' time. Indeed, a large longitudinal study showed that when parents who otherwise could not afford childcare received subsidies to make childcare possible, their children achieved higher educational and employment attainment compared to children whose parents did not receive subsidies when controlling for other factors (Havnes \& Mogstad, 2011).

Finally, we note that if screen time fills a need - namely, replacing adult supervision - there may be other means of fulfilling that same need. Not long ago, American children spent much of their time unsupervised, roaming the neighborhood with their peers. While cultural norms have changed, this provides a proof-of-concept that there are options for occupying children that involve neither screens nor adults.

\section{Author Contributions}

JKH designed the study. PMLPA and MDVM compiled Reelgood streaming data. JKH and PR conducted the analyses. $\mathrm{JKH}, \mathrm{PR}$, and $\mathrm{KO}$ wrote the manuscript, with input from YTH.

\section{Author Note}

The authors wish to thank $\mathrm{MCH}$ Strategic Data (www.mchdata.com/) and Reelgood (reelgood.com/business/products/catalog) for generously sharing their data, and Alex Ichimura for ad hoc research support and drafting Figure 1. Funding was provided by NSF awards to JKH (2030106) and YTH (2030160).

\section{Bibliography}

Adelantado-Renau, M., Moliner-Urdiales, D., CaveroRedondo, I., Beltran-Valls, M. R., Martínez-Vizcaíno, V., \& Álvarez-Bueno, C. (2019). Association between screen media use and academic performance among children and adolescents: A systematic review and metaanalysis. JAMA Pediatrics, 173(11), 1058-1067. https: //doi.org/10.1001/jamapediatrics.2019.3176

Aktay, A., Bavadekar, S., Cossoul, G., Davis, J., Desfontaines, D., Fabrikant, A., ... others. (2020). Google covid-19 community mobility reports: Anonymization process description (version 1.0). arXiv Preprint arXiv:2004.04145.

Alattar, L., Messel, M., \& Rogofsky, D. (2018). An introduction to the understanding america study internet panel. Soc. Sec. Bull., 78, 13.

American Academy of Pediatrics. (2016). Media and young minds. Pediatrics, 138(5). https://doi.org/10.1542/peds.2 016-2591

American Academy of Pediatrics. (2020). Finding ways to keep children occupied during these challenging times [Press release]. Retrieved from https://services.aap.org/e n/news-room/news-releases/aap/2020/aap-finding-waysto-keep-children-occupied-during-these-challengingtimes/

American Psychological Association. (2020a). Stress in the time of COVID-19: Volume one. Retrieved from https: //www.apa.org/news/press/releases/stress/2020/stress-inamerica-covid.pdf

American Psychological Association. (2020b). Stress in the time of COVID-19: Volume two. Retrieved from https: //www.apa.org/news/press/releases/stress/2020/reportjune 
Ashton, J. J., \& Beattie, R. M. (2019). Screen time in children and adolescents: Is there evidence to guide parents and policy? The Lancet Child $\mathcal{G}$ Adolescent Health, 3(5), 292294. https://doi.org/10.1016/S2352-4642(19)30062-8

Associated Press-NORC Center for Public Affairs Research. (2020a). The July 2020 AP-NORC Center Poll [Methodology statement and data set]. Retrieved from https://apno rc.org/wp-content/uploads/2020/07/topline_release2.pdf

Associated Press-NORC Center for Public Affairs Research. (2020b). The March 2020 AP-NORC Center Poll [Methodology statement and data set]. Retrieved from https: //apnorc.org/wp-content/uploads/2020/04/march202 0_topline.pdf

Bank, A. M., Barr, R., Calvert, S. L., Parrott, W. G., McDonough, S. C., \& Rosenblum, K. (2012). Maternal depression and family media use: A questionnaire and diary analysis. Journal of Child and Family Studies, 21(2), 208-216. https://doi.org/10.1007/s10826-011-9464-1

Bauer, L. (2020, May 6). The COVID-19 crisis has already left too many children hungry in America. Brookings Insitution: Up Front. Retrieved from https://www.brooki ngs.edu/blog/up-front/2020/05/06/the-covid-19-crisishas-already-left-too-many-children-hungry-in-america/

Collins, C., Landivar, L. C., Ruppanner, L., \& Scarborough, W. J. (2020). COVID-19 and the gender gap in work hours. Gender, Work $\mathcal{F}$ Organization. https: //doi.org/10.1111/gwao.12506

Cox, D. A., \& Abrams, S. J. (2020). The parents are not all right: The experiences of parenting during a pandemic. Washington, DC: American Enterprise Institute. Retrieved from American Enterprise Institute website: https://www.aei.org/wp-content/uploads/2020/07/AEIParenting-During-a-Pandemic-Survey-Report-1.pdf

Decker, S., Peele, H., Riser-Kositsky, M., Kim, H.-Y., \& Patti Harris, E. (2020, July 1). The coronavirus spring: The historic closing of U.S. schools. Education Week. Retrieved from https://www.edweek.org/ew/section/multimedia/thecoronavirus-spring-the-historic-closing-of.html

Edwards, S. M., \& Snyder, L. (2020, July 10). Yes, balancing work and parenting is impossible. Here's the data. The Washington Post. Retrieved from https: //www.washingtonpost.com/outlook/interruptionsparenting-pandemic-work-home/2020/07/09/599032e6b4ca-11ea-aca5-ebb63d27e1ff_story.html

Ferguson, C. J. (2017). Everything in moderation: Moderate use of screens unassociated with child behavior problems. Psychiatric Quarterly, 88(4), 797-805. https: //doi.org/10.1007/s11126-016-9486-3
Fisher, P., Lomardi, J., \& Kendall-Taylor, N. (2020, April 21). Why households with young children warrant our attention and support during (and after) the COVID-19 pandemic. Medium. Retrieved from https://medium.com /rapid-ec-project/why-households-with-young-childrenwarrant-our-attention-and-support-during-and-afterthe-b7cee9b76184

Glass, J., Simon, R. W., \& Andersson, M. A. (2016). Parenthood and happiness: Effects of work-family reconciliation policies in 22 oecd countries. American Journal of Sociology, 122(3), 886-929. https://doi.org/10.1086/688892

Guan, H., Okely, A. D., Aguilar-Farias, N., Pozo Cruz, B. del, Draper, C. E., El Hamdouchi, A., ... Veldman, S. L. C. (2020). Promoting healthy movement behaviours among children during the COVID-19 pandemic. The Lancet Child $\mathcal{E}$ Adolescent Health, 4(6), 416-418. https://doi.org/10.1016/S2352-4642(20)30131-0

Hamel, L., Kearney, A., Kirzinger, Ashley, Lopes, Lunna, Muñana, C., \& Brodie, M. (2020a). KFF Health Tracking Poll - July 2020 [Methodology statement and data set]. Kaiser Family Foundation. Retrieved from https: //www.kff.org/report-section/kff-health-tracking-polljuly-2020-methodology/

Hamel, L., Kearney, A., Kirzinger, Ashley, Lopes, Lunna, Muñana, C., \& Brodie, M. (2020b). KFF Health Tracking Poll - May 2020 [Methodology statement and data set]. Kaiser Family Foundation. Retrieved from https: //www.kff.org/report-section/kff-health-tracking-pollmay-2020-methodology/

Hamel, L., Lopes, L., Muñana, C., Kates, J., Michaud, J., \& Brodie, M. (2020). KFF Coronavirus Poll: March 2020 [Methodology statement and data set]. Kaiser Family Foundation. Retrieved from https://www.kff.org/corona virus-covid-19/poll-finding/kff-coronavirus-poll-march2020/

Hansen, T. (2012). Parenthood and happiness: A review of folk theories versus empirical evidence. Social Indicators Research, 108(1), 29-64. https://doi.org/10.1007/s11205011-9865-y

Havnes, T., \& Mogstad, M. (2011). No child left behind: Subsidized child care and children's long-run outcomes. American Economic Journal: Economic Policy, 3(2), 97129. https://doi.org/10.1257/pol.3.2.97

Johnson, A. D., \& Padilla, C. M. (2019). Childcare instability and maternal depressive symptoms: Exploring new avenues for supporting maternal mental health. Academic Pediatrics, 19(1), 18-26. https://doi.org/10.1016/j.acap.2 018.05 .006 
Kirzinger, A., Kearney, A., Hamel, L., \& Brodie, M. and. (2020). KFF Health Tracking Poll - Early April 2020: The impact of coronavirus on life in america [Methodology statement and data set]. Kaiser Family Foundation. Retrieved from https://www.kff.org/coronavirus-covid19/poll-finding/kff-coronavirus-poll-march-2020/

Lake, R., \& Dusseault, B. (2020 28). Remote classes are in session for more school districts, but attendance plans are still absent. The Lens. Retrieved from https: //www.crpe.org/thelens/remote-classes-are-session\%20more-school-districts-attendance-plans-are-still-absent

Lauricella, A. R., \& Cingel, D. P. (2020). Parental influence on youth media use. Journal of Child and Family Studies, 29(7), 1927-1937. https://doi.org/10.1007/s10826-02001724-2

Madigan, S., McArthur, B. A., Anhorn, C., Eirich, R., \& Christakis, D. A. (2020). Associations between screen use and child language skills: A systematic review and meta-analysis. JAMA Pediatrics, 174(7), 665-675. https: //doi.org/10.1001/jamapediatrics.2020.0327

Masonbrink, A. R., \& Hurley, E. (2020). Advocating for children during the COVID-19 school closures. Pediatrics, 146(3). https://doi.org/10.1542/peds.2020-1440

Moore, S. A., Faulkner, G., Rhodes, R. E., Brussoni, M., Chulak-Bozzer, T., Ferguson, L. J., ... Tremblay, M. S. (2020). Impact of the COVID-19 virus outbreak on movement and play behaviours of canadian children and youth: A national survey. International Journal of Behavioral Nutrition and Physical Activity, 17(1), 85. https://doi.org/10.1186/s12966-020-00987-8

New York Times. (2020). Coronavirus (Covid-19) data in the United States. Retrieved from https://github.com/nytimes /covid-19-data

Nikken, P. (2019). Parents' instrumental use of media in childrearing: Relationships with confidence in parenting, and health and conduct problems in children. Journal of Child and Family Studies, 28(2). https://doi.org/10.1007/ s10826-018-1281-3

Nomaguchi, K. M. (2012). Parenthood and psychological well-being: Clarifying the role of child age and parentchild relationship quality. Social Science Research, 41(2), 489-498. https://doi.org/10.1016/j.ssresearch.2011.08.0 01

O'Reilly, L. (2020, March 20). With schools shut, kids linear TV ratings are on the up. Digiday. Retrieved from https://digiday.com/media/schools-shut-kids-linear-tvratings/
Oswald, A. R. A. K., Tassia K. AND Rumbold, \& Moore, V. M. (2020). Psychological impacts of "screen time" and "green time" for children and adolescents: A systematic scoping review. PLOS ONE, 15(9), 1-52. https: //doi.org/10.1371/journal.pone.0237725

ParentsTogether. (2020, April 23). Survey shows parents alarmed as kids' screen time skyrockets during COVID-19 crisis [Press release]. Retrieved from https://parentstogether.org/survey-shows-parents-alarmed-as-kidsscreen-time-skyrockets-during-covid-19-crisis/

Parkes, A., Sweeting, H., \& Wight, D. (2015). Parenting stress and parent support among mothers with high and low education. Journal of Family Psychology, 29(6), 907. https://doi.org/10.1037/fam0000129

Pempek, T. A., \& McDaniel, B. T. (2016). Young children's tablet use and associations with maternal wellbeing. Journal of Child and Family Studies, 25(8), 26362647. https://doi.org/10.1007/s10826-016-0413-x

Przybylski, A. K., \& Weinstein, N. (2019). Digital screen time limits and young children's psychological well-being: Evidence from a population-based study. Child Development, 90(1), e56-e65. https://doi.org/10.1111/cdev.13007

RAPID-EC Research Group. (2020, June 2). Between a rock and a hard place. Medium. Retrieved from https://medium.com/rapid-ec-project/between-a-rockand-a-hard-place-245857e79d9d

Schmidt, M. E., Haines, J., O’Brien, A., McDonald, J., Price, S., Sherry, B., \& Taveras, E. M. (2012). Systematic review of effective strategies for reducing screen time among young children. Obesity, 20(7), 1338-1354. https://doi.org/10.1038/OBY.2011.348

Stiglic, N., \& Viner, R. M. (2019). Effects of screentime on the health and well-being of children and adolescents: A systematic review of reviews. BMJ Open, 9(1). https://doi.org/10.1136/bmjopen-2018-023191

SuperAwesome. (2020). Everyone is a kids and family brand now: Data, observations and recommendations for companies interacting with kids and families during lockdown. Retrieved from https://www.superawesome.com/everyon e-is-a-kids-and-family-brand-now/

Understanding America Study. (2020). Understanding America Study methodology. Brookings Institution.

U.S. Census Bureau. (2019). State population totals and components of change: 2010-2019. Retrieved from https://www.census.gov/data/tables/time-series/dem o/popest/2010s-state-total.html\#par_textimage_15744 39295,\%202019\%20estimates\%0A 
Van Lancker, W., \& Parolin, Z. (2020). COVID-19, school closures, and child poverty: A social crisis in the making. The Lancet Public Health, 5(5), e243-e244. https: //doi.org/10.1016/S2468-2667(20)30084-0

Viner, R., Davie, M., \& Firth, A. (2019). The health impacts of screen time: A guide for clinicians and parents. The Royal College of Paediatrics and Child Health. Retrieved from The Royal College of Paediatrics and Child Health website: https:/www.rcpch.ac.uk/sites/default/files/201812/rcpch_screen_time_guide_-_final.pdf

World Health Organization. (2019). Guidelines on physical activity, sedentary behaviour and sleep for children under 5 years of age. Retrieved from https://www.who.int/ publications/i/item/guidelines-on-physical-activity- sedentary-behaviour-and-sleep-for-children-under-5years-of-age\#: :text $=$ The $\% 20 \mathrm{WHO} \% 20$ Guidelines $\% 20$ on $\% 20$ physical, wellbeing\%2C\%20and\%20the $\% 20 \max$ imum\%20recommended

Wozniak, A., Willey, J., Benz, J., \& Hart, N. (2020). COVID Impact Survey: Version 1.3, 2.2, and 3. National Opinion Research Center. Retrieved from https://www.covidimpact.org/results

Xiang, M., Zhang, Z., \& Kuwahara, K. (2020). Impact of COVID-19 pandemic on children and adolescents' lifestyle behavior larger than expected. Progress in Cardiovascular Diseases. https://doi.org/https://doi.org/10.1 016/j.pcad.2020.04.013 